creased the usefulness of his book by listing them for reference and citing them in the proper place in the text.

As it stands, the book is certain to offer much stimulation to further research and exploration. The descriptions will be developed by local study and the principles and laws will be tested by comparison, discussion and new investigations.

Department of Botany, Pterre Dansereau

UNIVERSity OF Michigan, Ann ARBor, Michigan

\title{
INTEGRATION OF THE ECOSPECIES ${ }^{1}$
}

The eternally disputed definition of species is very sharply focused in Jens Clausen's book, "Stages in the evolution of plant species." The outstanding merit of this work is that it summarizes very lucidly the experiments on the nature of species which Hall had begun but which are principally Clausen's own work and that of his collaborators David D. Keck and Wm. M. Hiesey at the Carnegie Institution of Washington's Department of Plant Biology in Stanford, California. The past decade has been a very fruitful one for this group, as the essentials and much of the detail of their experimental work have been made known in print. The soundness of their method, the thoroughness of their investigations and the variety of their respective backgrounds offered unique guarantees of original and significant research. Their three book-length memoirs and their many shorter papers had provided us with a great wealth of new materials and many leads to new interpretations. The present book goes a step beyond this and outlines Clausen's (and presumably his collaborators') emergent concept of speciation. This is far-reaching indeed, although the author does not pretend to review the whole field of experimental taxonomy, even less the more general topic of evolution. In fact, it justifies its title perfectly by casting complete emphasis on experimentally known cases of perfect to imperfect to inadequate isolation of taxa in the Western North American environment. Some of the author's earlier work in Northwestern Europe is also quoted, as are Brainerd and Gershoy's in Eastern North America. But no one will quarrel with Clausen's dwelling principally on what he knows best: a central Californian transect from the Pacific across the coastal ranges and inner valleys to the slopes and summits of the Sierra Nevada, thence down to the deserts of the Great Basin. Such a transect lends itself extremely well to a test of evolutionary processes as it provides strongly contrasting environmental backgrounds at close intervals. Even though such telescoping is not unique, it is in many ways peculiar and the rates of change and the

1 Clausen, Jens. 1951. Stages in the evolution of plant species. viii +206 pp., 76 figs., Ithaca: Cornell University Press, $\$ 3.75$. very mechanisms observed are sure to be quite different in other parts of the world with broad instead of narrow life zones. Stebbins for instance (Am. Nat., 86 (826) : 34, 1952) ventures to "predict that the diversity of ecotypes of individual species, when investigated will prove to be considerably less" in the Eastern States than in California.

The book consists of eight chapters. The first two offer a brief historical perspective in which the growing influence of genetics on taxonomy is emphasized. The principal currents are outlined: Darwin's keen observations of variation in nature and its obedience to natural selection; the experimental approach and discovery of the mechanics of heredity by Mendel's successors. These two traditions, which to some extent had followed separate courses, are joined harmoniously in Turesson's work. The often overlooked evolutionary ideas of Linnaeus in his later years are quoted as marking the beginning of a "modern" point of view. Jordan is credited with the discovery of the local population.

This is the subject of the third chapter, "The local population as the basic evolutionary unit." Here the author's working principles are clearly stated: "It is at the level of the local population that all of the selective forces act upon the genetic resources of the population." This statement is well illustrated and substantiated by examples from the genera Layia, Viola, Potentilla, and Achillea. Following the best in taxonomic tradition, intra-population and interpopulation variations are compared and found to be of a different order of magnitude (p. 26). However, these analyses are always made in the light of the deeper-lying physiological responses which are elicited by the heredity vs. environment contest. Thus: "It is probable that the intrapopulation variation enables a species to tolerate periodic variations in the climate at any one locality."

These various points are strikingly illustrated by experimental data, the conclusiveness of which is quite incontestable. One might wish, however, that Clausen's rejection of other techniques for estimating populations "growing in the wild and therefore subjected to uncontrolled modifications in many environments" were the object of further discussion. The work of Edgar Anderson, Fassett, and Woodson is not men- 
tioned. It would be interesting to compare purpose and achievement in both cases and to outline what aspects of environmental integration are revealed by these different means. It seems, however, that both groups will agree that "clines are not commensurable with natural entities," if by the latter are meant formal taxa.

The fourth chapter concerns "the evolution of ecological races." Whereas the preceding chapter had not provided a hard and fast definition of the local population, the present definition of the ecological race may seem unsatisfactory: "An ecological race is usually composed of a considerable number of variable local populations existing within a given ecological zone." This latter term itself is not defined either, except by implication. A short paragraph on parts of pp. 50-52 states that "these major sets of factors in the environment have been decisive in the development of ecological races, namely, climate, soils, and other organisms. All of these three are interrelated and contribute to natural selection, but climatic, edaphic, or biotic ecotypes can be recognized, depending upon which of these sets of factors has been relatively the most dominant."

I can voice no objection to the above statements but $I$ am afraid they lend themselves to a variety of rather divergent applications. Whereas a constant attempt is being made to assess morphological, genetic, cytological and physiological criteria and to assemble them in a discriminating way so as to reflect a natural hierarchy (Chapter VIII), and whereas the magnitude of each "stage in the evolution of plant species" is graded, no corresponding hierarchy in the environment as a whole is indicated. Transgressions by the segments of a species beyond the barriers of biotope, community, habitat, climatic zone are not recognized explicitly as such.

Clausen does not say that hierarchy in environment (a) does not exist; $(b)$ is too complex to be measured effectively; $(c)$ is not significant, since the ultimate unit alone is considered. For instance, Figure 5 (p. 20) shows 4 subspecies of Potentilla glandulosa as they occur from 900 to 11,000 feet on the west slope of the Sierra Nevada. As far as major climatic and vegetation zones are concerned, 6 distinct units are involved : 1) the oak savana, 2) the yellow pine forest (or woodland), 3) the red fir forest, 4) the lodgepole pine woodland, 5) the white-bark pine scrub and 6) the alpine meadow. Ssp. typica is found only in 1 ; ssp. reflexa in 1 and 2 ; ssp. hanseni in 2 and 3 ; ssp. nevadensis in 4,5 , and 6 . The case of reflexa and hansen is an interesting one as they overlap to a considerable extent geographically (and therefore climatically), but remain distinct ecologically
Thus some local populations of both subspecies share the same amounts of rainfall and heat except inasmuch as their habitats ("sunny slope" and "meadow") utilize the meteorological elements differently and eventually provide the plants themselves with rather different amounts of heat and water, and at different times also. There is here an ecological dimension that fits into a climatic dimension. There is also the further question of ecological amplitude, not necessarily similar or even parallel to climatic tolerance. ${ }^{2}$ Although these issues are certainly present in the author's mind, they are not as sharply focused as the corresponding morphological and genetic aspects.

In the fifth chapter the genetic systems which underlie the adjustment of taxa are reviewed, whether or not the units involved show any morphological discreteness. The point is well made that some formerly adaptive features are able to persist after a shift and even a reversal in the kind of environmental pressure exerted. Thus a "typically maritime" Viola tricolor (from Denmark) was grown in inland California and eventually sowed itself in a garden at Santa Rosa, maintaining its identity under "drastic changes." 8

Several good examples are provided here that illustrate the degrees of effectiveness in genetic isolation. It is assumed that the best proof thereof lies in the failure to cross-breed or in the relative weakness of the offspring. Thus the background is drawn for the principal argument of the book which will culminate in a grading (Chapter VIII) of the isolating mechanisms. The largest stock of evidence along these lines is drawn from taxa indigenous to at least one of the three stations (Stanford, Mather, Timberline) operated by Clausen and his collaborators. The relative frequency of successful experimental crossing on the one hand, and the degree of survival and "vigour"

${ }^{2}$ A plant like Chamaedaphne calyculata ranges from the near-Arctic to the mountains of Georgia, is exposed to a variety of severe and mild climates. Ecologically it is very narrow, however, being strictly confined to bogs, and even to a certain phase of bog formation. On the contrary, Betula populifolia has rather a narrow range (Atlantic-North Appalachian) but very wide ecological amplitude : sand plains, bogs, old fields, stream edges, rock outcrops, etc.

A similar case is that of Veronica peregrina var. laurentiana, an estuarine ecospecies now selfsown in the Montreal Botanical Garden where it maintains its identity perfectly. (M. Raymond and J. Kucyniak in Contrib. Inst. Bot. Univ. Montréal, 62: 19.1947 ). 
in each one of the three stations on the other hand, show both the amount of divergence between related taxa and the amount of relative fitness of each to its station, although not as obviously to its habitat (s), even less to its community (ies).

Chapter VI outlines "the evolution of interspecific barriers," starting with a "situation within species where such barriers have not yet started to evolve," or at least where they are not effective because of gene flow through intermediate segments.

Although "there are numerous ways in which groups of populations and races may become genetically isolated... the most normal pattern of speciation .... is a more or less simultaneous and gradual separation in morphologic, ecologic, genetic, and cytologic characteristics." Clausen then goes on to review "groups having predominantly ecological barriers," "predominantly morphological differentiation," "predominantly genetic barriers." These three different kinds of taxa are amply illustrated by Californian examples, each type showing well-defined characteristics both in morphology and behaviour.

As weak barriers tend to become strong, so scarcely separable units separate further, and better individualized taxonomic units result. In Chapter VII, the author applies the foregoing principles and further synthesizes the wealth of facts at his command to describe "the evolution of groups of species." The genera Layia, Madia, and Hemizonia in California show very distinct patterns which are essentially the result of different degrees of divergence at all levels, from the local population to the genus. The violets, on the other hand, offer a more complex situation, a greater variety of evolutionary patterns, which is only in part due to their wide geographical distribution.

The last chapter, entitled "The physiologicgenetic species concept and the dynamics of the evolution of species and genera" offers a concise but extremely lucid review of the sources of genetic variability and the means by which it is produced. The excellent Figure 72 shows at a glance the "building blocks" of heredity (genes, chromosome segments, chromosomes, genomes), the process by which they operate (creative mutation, recombination, loss, duplication, addition); and the evolutionary level on which they function (intra- or inter-specific). Two further tables (74 and 75) offer a key to a rational taxonomic hierarchy of categories based on the principles previously outlined and tested. This codification of the dynamic aspects of speciation which has now been forced to the attention of even the most conservative systematists will be most welcome. It seems that comparia, cenospecies, ecospecies are necessary terms at this time, although taxonomists are justly reluctant to speak in terms of "morphological species" and "genetic species" (terms which are generally avoided in this book. Rather they are willing to test this and that taxon by the use of new criteria (genetic, ecological, and otherwise) and to redefine and recast them nearer to experimentally known reality without deviating from the classic nomenclature. This however is essentially a "legal" point of obviously little biological interest. It remains that the experimental taxonomist, when he deals in ecospecies, cenospecies, etc., has a more unequivocal term than the taxonomist whose categories are for the most part untested.

Clausen's book is an exceedingly important one to ecologists. If their research is concerned with autecological relationships, they can make no beginning unless they constantly bear in mind the phenomena which are so capably outlined here, unless they are at all times aware of the underlying mechanisms of variability in local populations and ecological races and become able to detect them. Although this little book does not cover all phases of the integration of plants in their environment-which is indeed not its purpose-it so sharply focuses the genetic substratum of adaptation that it provides a useful background for practically all cases.

If the ecologist's research concerns synecology, he will find much that is lacking in this book. $\mathrm{He}$ will regret that synecological concepts are nowhere as clear as are genetic and taxonomic concepts. He may feel that much has been said concerning the inherent mechanisms of hereditary transmission, their emergent result as moulders of minor or major taxa; that much has been made also of natural selection as a controlling force. But he will find that it is not too clear what the taxa which are used as examples have become or are becoming adapted to! He will also honestly have to admit that ecologists, as yet, have hardly provided workers in other fields with a satisfactory repertorium of units as manageable as the species of the taxonomist or the genome of the geneticist. This task lies ahead; now that ecospecies and ecotypes are beginning to be known, it will be worth while to project them against the smallest environmental units that contain them and to evaluate natural selection in terms of the kind, quantity, and durability of pressures that govern their dynamics.
Pierre Dansereau
Department of Botany, University of Mrchigan, Ann Arbor, Michigan 